\title{
Rancang Bangun Pengontrolan Suhu dan Kelembaban pada Proses Fermentasi Tempe Berbasis Internet of Things
}

\author{
Berdi Gunawan ${ }^{1}$, Sukardi ${ }^{2}$ \\ 1,2 Universitas Negeri Padang \\ Jl. Prof Dr. Hamka Air Tawar, Padang, Indonesia \\ bbguna56@gmail.com¹ sukardiunp@ft.unp.ac.id²
}

\begin{abstract}
The traditional tempeh process takes 30 to 36 hours, to convert raw soybeans into finished tempeh. The processing of tempeh can affect the marketing time and affect the tempe which is easily blackened if the fermentation period of the tempe is too long. So an idea emerged to create a tool that could monitor and control the fermentation process using the internet. This fermentation tool works in a temperature range of $30^{\circ} \mathrm{C}-35^{\circ} \mathrm{C}$. In this temperature range, the fermentation time of raw soybean tempe will turn into tempe, so it takes 16 hours. The tempe process monitoring tool uses a DHT 22 sensor. This tool is controlled by a NodeMCU microcontroller. In this tool, temperature monitoring is carried out through the DHT22 sensor, if the temperature is lower than the set point then NodeMCU will carry out the ON command on the lamp and if the set point temperature is higher than the specified then NodeMCU will perform the OFF command on the lamp, and arrive at the set point time limit. which is determined. The readings can be monitored using an application connected to the internet.
\end{abstract}

Keywords-sensor DHT22, NodeMCU, Blynk, Tempe

\begin{abstract}
Abstrak- Proses tempe tradisional butuh waktu 30 sampai 36 jam, untuk mengubah kedelai mentah menjadi tempe jadi. Lamanya proses pengolahan tempe dapat mempengaruhi waktu pemasaran serta mempengaruhi ragi tempe yang mudah menghitam jika terlalu lama masa fermentasi tempe. Maka muncul sebuah ide untuk membuat sebuah alat yang bisa memonitoring dan mengontrol proses fermentasi tempe menggunakan internet. Alat fermentasi ini bekerja pada rentang suhu $30^{\circ} \mathrm{C}-35^{\circ} \mathrm{C}$. Pada rentang suhu tersebut, waktu fermentasi tempe kedelai mentah akan menjadi tempe jadi butuh 16 jam. Pada alat proses monitoring tempe menggunakan sensor DHT 22. Alat ini dikontrol dengan mikrokontrolker NodeMCU. Pada alat ini dilakukan monitoring suhu melalui sensor DHT22, jika suhu lebih rendah dari set point maka NodeMCU akan melakukan perintah ON pada lampu dan jika set point suhu tinggi dari yang ditentukan maka NodeMCU akan melakukan perintah OFF pada lampu, dan sampai pada batas set point waktu yang ditentukan. Hasil pembacaan dapat dipantau menggunakan aplikasi blynk yang terhubung ke internet.
\end{abstract}

Kata kunci-sensor DHT22, NodeMCU, Blynk, Tempe

\section{Pendahuluan}

Tempe merupakan sumber bahan pangan yang memiliki kandungan gizi yang bagus, dan serta harga yang terjangakau memudahkan masyarakat di indonesia sering mengkonsumsi tempe setiap harinya. Tempe dibuat dengan bahan utama yaitu biji kedelai serta beberapa bahan lain yang menunjang proses fermentasi seperti beberapa jenis kapang Rhizopus oligosporus, Rh. oryzae, Rh. stolonifer (kapang roti), atau Rh. arrhizus. Tempe selalu dijadikan menu utama oleh sebagian besar masyarakat indonesia [1]. Maka itu banyak insdustri kedelai mengolah menjadi tempe yang bagus untuk dikonsumsi masyarakat indonesia mulai pembuatan yang mudah serta bahan baku yang mudah ditemukan. tetapi muncul kendala diindustri tempe bahwa pembuatan fermentasi tempe dipengaruhi oleh suhu dan kelembaban disekitarnya mulai dari musim hujan, kemarau dan kebersihan lingkungan. Pada proses pembuatan tradisional memakan waktu 30 jam hingga 2 hari lamanya dan pembuat tempe kurang memahami suhu dan kelembaban yang baik dalam proses pembuatan tempe. maka itu dibutuhkan sebuah alat yang dapat mengatasi masalah tersebut.

Beberapa studi mengenai proses fermentasi tempe dengan sistem kendali suhu dan kelembaban otomatis telah banyak dilakukan, seperti dalam sistem kendali suhu dan kelembaban untuk optimasi pembuatan tempe dengan sensor suhu DHT11, alat ini menggunakan whater heater (pemanas air). Namun alat ini masih memiliki kekurangan, yaitu tidak memberikan pengaruh yang signifikan pada kelembaban tempe [2]. Studi lainnya seperti rancang bangun alat sistem kontrol suhu dan kelembaban fermentasi tempe menggunakan sistem fuzzy logic, sistem ini membutuhkan waktu fermentasi yang lama sekitar 20 jam [3]. Selanjutnya studi tentang sistem kotrol suhu dan kelembaban menggunakan mikrokontroler dengan LCD Blue Led Display [4]. Alat fermentasi sejenis juga pernah dibuat, yaitu inkubator fermentasi kulit singkong 
menggunakan sensor DHT11, studi ini dilengkapi keypad dan LCD 4 X 20 sebagai User Interface dimana pengguna harus selalu mengontrol alat sampai proses fermentasi selesai, sehingga menyulitkan pengguna dalam pengoperasian alat tersebut [5].

Alat ini menggunakan menggunakan NodeMCU sebagai pusat kontrol sistem kerja alat, DHT22 sebagai pengukur tingkat suhu dan kelembaban, LCD 16x2 sebagai penampil suhu dan kelembaban, lampu yang dikontrol oleh relay sebagai media pemanas, alat ini menggunakan aplikasi Blynk yang terkoneksi ke internet sebagai pusat monitoringnya, NodeMCU sebagai penghubung internet dengan aplikasi Blynk.

\section{Metode}

Dalam proses perancangan dan pembuatan alat ini terdiri dari perncangan hardware dan software. Pada perancangan hardware terdiri komponen NodeMCU, Relay 4 chanel, Sensor DHT22, Kipas, Lampu, LCD, RTC, dan Catu daya. Pada perancangan software menggunakan software Arduino IDE dan aplikasi Blynk.

Pada aplikasi blynk dapat dilakukan monitoring dengan penampilan parameter suhu dan kelembaban yang dibaca sensor DHT22 ditampilkan secara realtime kepada pengguna melalui smartphone.

\section{HASIL DAN PEMBAHASAN}

\section{A. Blog Diagram}

Sebelum merancang alat, dengan membuat blok diagram dapat lebih mudah menjelaskan sistem kerja perangkat yang akan dibuat. Adapun blok diagram Alat fermentasi tempe dapat dilihat pada gambar dibawah ini.

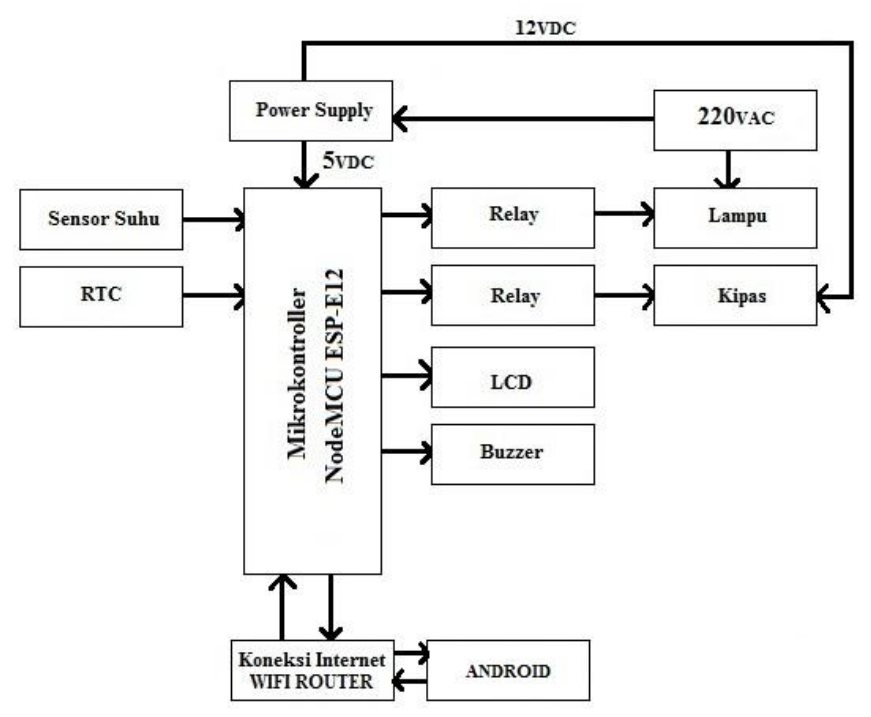

Gambar 1. Blog diagram

Diagram blok ini dapat dijelaskan sebagai berikut:

1. Sensor DHT
Sensor DHT11 ini sangat akurat dalam pembacaan suhu dan kelembaban karna sensor ini didukung fitur kalibrasi. Data yang telah dikalibrasi tersebut disimpan pada memori program OTP yang disebut juga dengan koefisien kalibrasi [6].

2. Mikrokontroller NodeMCU ESP-E12

Mikrokontroler berfungsi sebagai pengendali sistem secara keseluruhan, Input analog pada ESP$12 \mathrm{E}$ ini memiliki tegangan maksimal 3.3Volt. Sedangkan pada konverter dari PC ke ESP-12E menggunakan IC CP2102 dan tegangan kerjanya 5 VDC [7] dan prosesor utama yang digunakan untuk melakukan proses pengolahan data. Dan terkoneksi dengan wifi dan internet.

3. Relay

Relay sebagai eksekutor rangkaian delay (tunda) Relay sebagai protektor atau pemutus arus pada kondisi tertentu [8].

4. RTC

RTC (Real time clock) adalah jam elektronik berupa chip yang dapat menghitung waktu (mulai detik hingga tahun) dengan akurat dan menjaga/menyimpan data waktu tersebut secara real time.

5. LCD

LCD merupakan suatu alat yang berfungsi untuk menampilkan angka suhu dan kelembaban yang terbaca oleh sensor.

6. Kipas

Secara umum Motor DC meruapakan piranti yang dapat mengkonversikan dari energi listrik menjadi energi gerak putaran, fungsi dari Motor DC pada alat ini sendiri yaitu untuk menggerakan baling kipas agar setpoint suhu yang diinginkan tetap tercapai [9].

7. Lampu

Lampu pijar merupakan pemanas dan sumber cahaya yang didapat memalui aliran arus listrik pada filamen yang terdapat pada lampu pijar itu sendiri. Filamen tersebut ditutupi tabung kaca utnuk menghalangi udara luar agar tidak terjadi kerusakan pada filamen akibat teroksidasi [10].

\section{B. Cara Kerja Alat}

Pada blok diagram dapat dijelaskan, Sistem pengendali suhu dan kelembaban ruang fermentasi tempe ini mempunyai 1 buah sensor sebagai input yaitu sensor suhu dan kelembaban DHT11. Suhu yang terdeteksi oleh sensor kemudian dikirim pada mikrokontroller NodeMCU ESP E-12 yang akan memproses data suhu dan kelembaban yang didapatkan. Selanjutnya NodeMCU akan meneruskan data yang terbaca oleh sensor untuk ditampilkan pada LCD. Data suhu dan kelembaban yang 
terbaca oleh sensor juga akan diproses oleh NodeMCU untuk mengendalikan relay lampu pijar.

Saat suhu terbaca oleh sensor DHT22 rendah dari $30^{\circ} \mathrm{C}$, buzzer akan menyala sebagai pemberi peringatan bahwa suhu pada ruangan fermentasi berkurang maka relay 1 akan bekerja untuk membuat lampu menyala, sedangkan saat suhu terbaca oleh sensor DHT22 yaitu besar dari $>30^{\circ} \mathrm{C}$ kecil dari $<35^{\circ} \mathrm{C}$ maka relay 1 akan bekerja untuk membuat lampu akan menyala dan saat suhu terbaca oleh sensor DH22 mendekati batas suhu maksimum yaitu 35으 maka relay 1 akan bekerja untuk membuat lampu ruangan mati dan sampai suhu dan kelembaban dalam ruangan kembali stabil pada range suhu dan kelembaban yang ditentukan.

Relay 2 akan bekerja untuk membuat Kipas mati apabila suhu terbaca oleh sensor DHT22 rendah dari $30^{\circ} \mathrm{C}$ sedangkan relay 2 akan bekerja untuk membuat kipas menyala apabila suhu terbaca oleh sensor DHT11 yaitu besar dari $>30^{\circ} \mathrm{C}$ kecil dari $<35 \stackrel{\circ}{\circ} \mathrm{C}$ maka relay 2 akan bekerja untuk membuat kipas akan menyala dan saat suhu terbaca oleh sensor DHT11 melebihi 35으 maka relay 2 akan bekerja untuk membuat kipas menyala. Fungsi kipas pada alat sistem pengontrolan suhu dan kelembaban ini yaitu untuk meratakan suhu dan kelembaban keseluruh ruangan proses fermentasi tempe.

LCD pada alat ini berfungsi sebagai menampilkan suhu dan kelembaban yang terbaca oleh sensor DHT11 dalam box fermentasi tempe yang bisa dipantau secara manual oleh si pemilik alat.

Blynk berfungsi sebagai pemantauan dan pengontrolan jarak jauh kepada si pemilik alat melalui perintah NodeMCU yang mana untuk memberi taukan si pengguna alat bahwasannya tempe sudah diangkat pada alat fermentasi tempe.

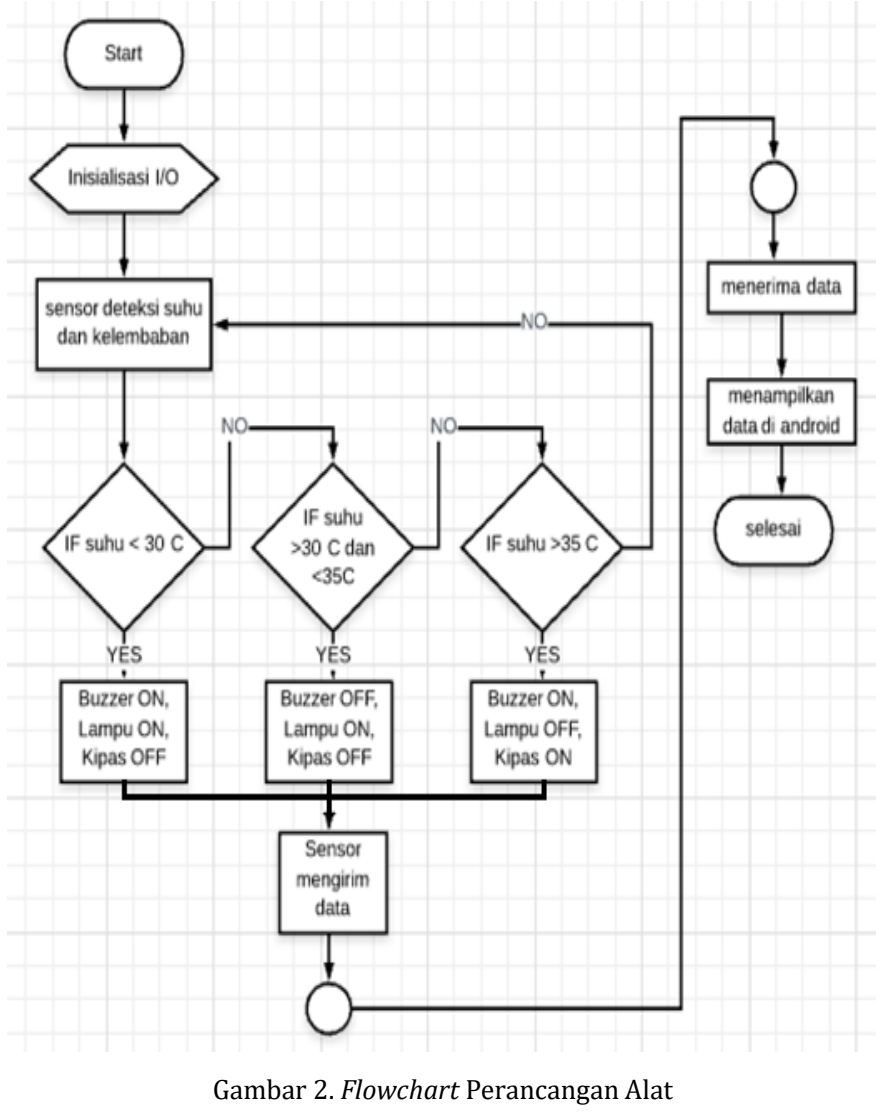

\section{Perancangan Hardware}

Perancangan hardware (mekanik) bertujuan untuk menentukan tata letak dari peralatan yang akan dibuat.

1. Perancangan Bentuk Alat.

Perancangan mekanik pada alat ini dibuat dengan software SketchUp, mekanik yang dirancang terdiri dari sebuah kotak kontrol dan ruang inkubator dengan ukuran 40x50x85.

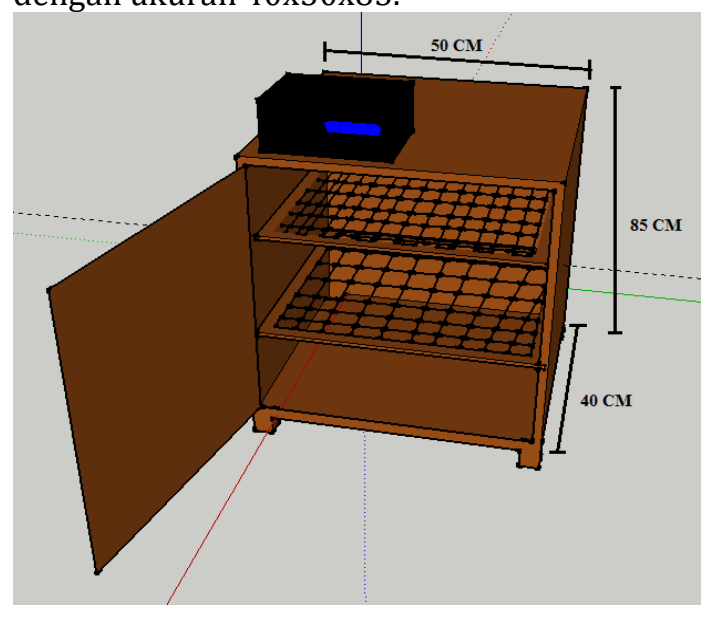

Gambar 3. Bentuk alat tampak depan 
D. Rangkaian Keseluruhan

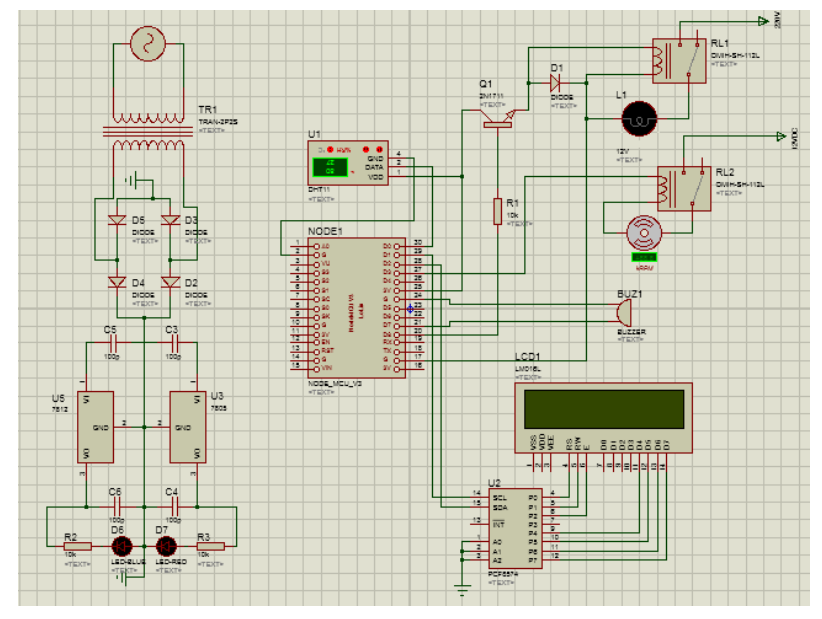

Gambar 4. Rangkaian keseluruhan

E. Perancangan Aplikasi Android

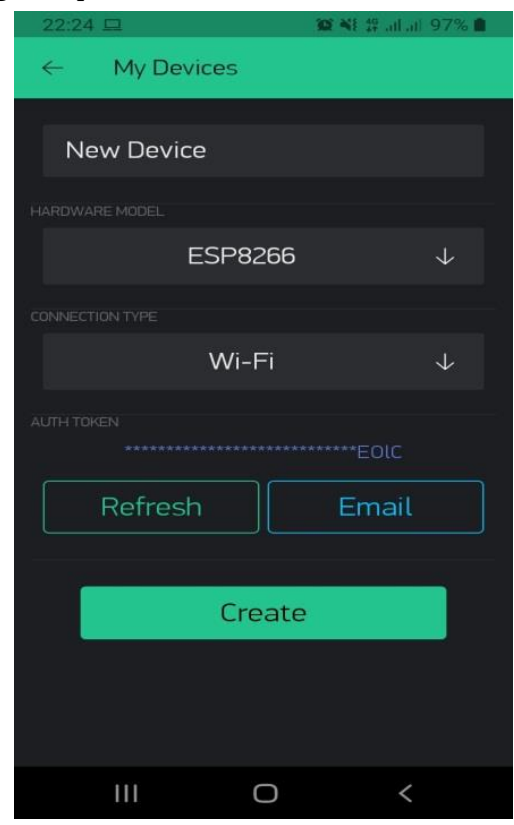

Gambar 5. Aplikasi Android

\section{HASIL DAN PEMBahasan}

A. Hasil Pengujian Catu Daya Kontrol Ruang Inkubator

Pengujian pada sistem ruang inkubator fermentasi ini disuplai dengan sumber tegang PLN 220 Vac dengan menggunakan trafo stepdown dan rangkaian penyearah untuk menghasilkan tegangan $5 \mathrm{Vdc}$ untuk suplai tegangan kontrol dan $12 \mathrm{Vdc}$ suplai kipas untuk ruang inkubator.

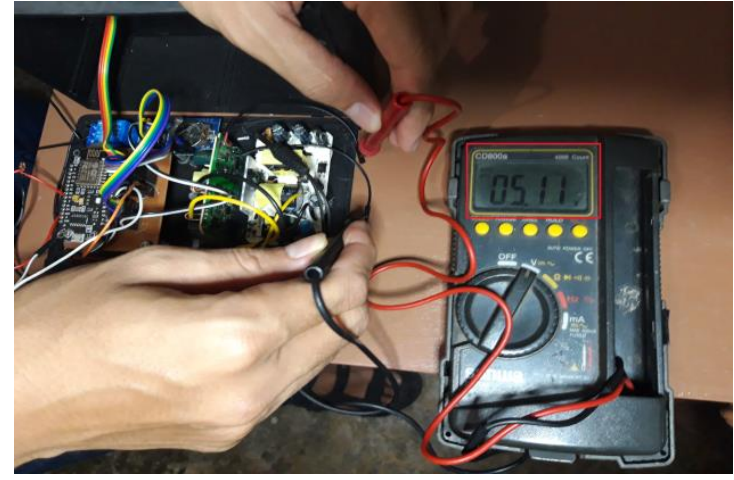

Gambar 6. Pengujian catudaya 5 Vdc

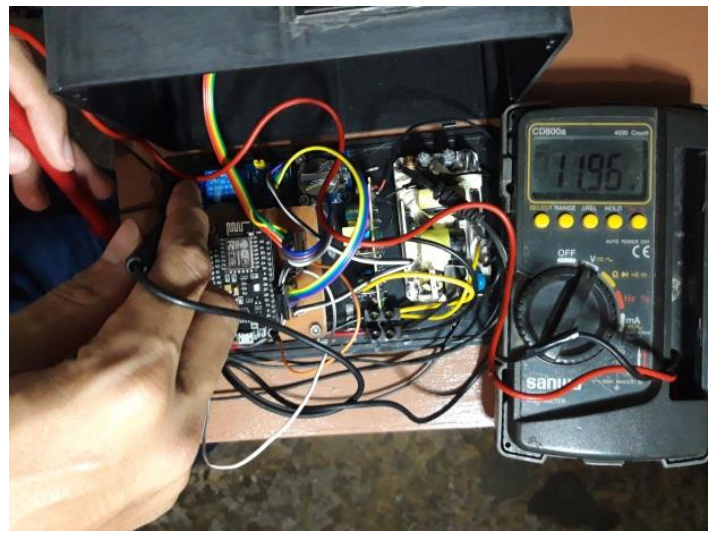

Gambar 7. Pengujian catudaya 12 Vdc

Dari pengujian diatas dapat dilihat bahwa didapatkan hasil nilai kesalahan sebesar 2,1\% dengan tegangan didapat 5,11 Vdc untuk pengukuran tegangan 5 Vdc. Sedangkan pada tegangan 12 Vdc didapatkan sebesar 3,3\% dengan pengukuran yang didapatkan 11,96 Vdc.

\section{B. Pengujian Sensor DHT22}

Pengujian sensor DHT22 berguna untuk membandingkan pembacaan nilai pada sensor suhu dan alat ukur. Alat ukur yang digunakan sebagai pembanding suhu menggunakan alat ukur Cobra 4 2x Temperature NiCr-Ni. Pada pengujian sensor DHT22 akan diuji dengan alat ukur dengan mengetahui suhu pada ruang inkubator.

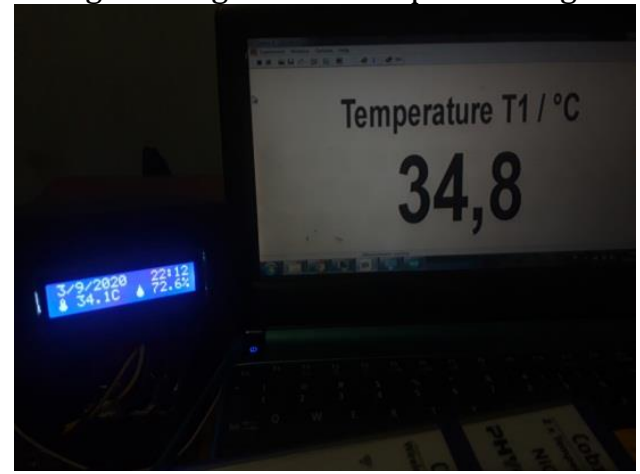

Gambar 8. Pengujian suhu sensor 
Dari pengujian menggunakan alat ukur dapat dilihat perbandingan suhu pada alat ukur terbaca $34,8^{\circ} \mathrm{C}$ sedangkan pada sensor DHT22 terbaca $34,1^{\circ} \mathrm{C}$ dimana selisih antara sensor dan alat ukur hanya $0,7^{\circ} \mathrm{C}$ dan dapat disimpulkan bahwa persentase kesalahan pada pengujian sensor sebesar $2 \%$.

\section{Pengujian Relay}

Pegujian ini bertujuan untuk mengetahui kerja relay terutama untuk bagian lampu dan kipas. Sebab alat ini menggunakan lampu pijar sebagai pemanas untuk menaikan suhu dan kipas sebagai menurun suhu. Dimana relay berguna untuk mengontrol kerja alat, saat sensor suhu mendeteksi suhu kecil dari $32^{\circ} \mathrm{C}$ maka relay lampu akan mengaktifkan lampu pemanas dan ketika suhu terdeteksi besar dari $35^{\circ} \mathrm{C}$ maka relay akan mengaktifkan kipas untuk mengontrol suhu dibawah $35^{\circ} \mathrm{C}$.

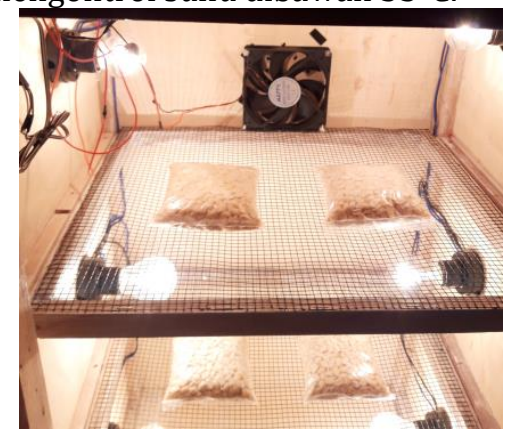

Gambar 9. Pengujian relay lampu, suhu dibawah $32^{\circ} \mathrm{C}$ (lampu aktif semuanya)

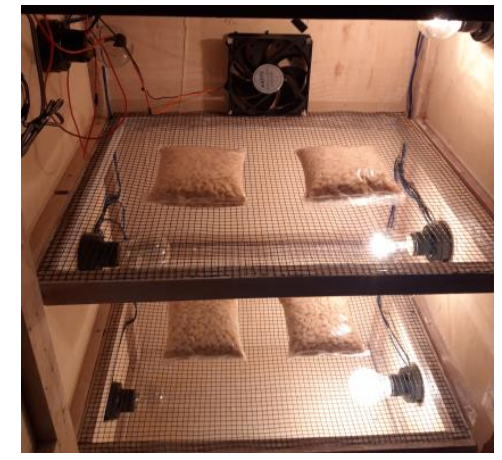

Gambar 10. Pengujian relay lampu, suhu diatas $35^{\circ} \mathrm{C}$ (lampu aktif sebagian dan kipas aktif)

\section{Pengujian Inkubator fermentasi}

Pengujian inkubator fermentasi ini bertujuan untuk mengetahui kerja alat apakah berjalan sesuai dengan set point yang telah ditentukan. Dengan cara memasukan objek berupa tempe mentah kedalam inkubator dan mengaktifkan sistem keseluruhan.

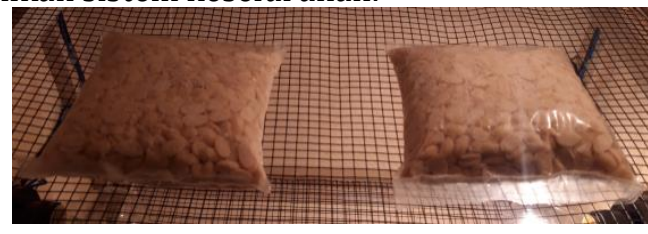

Gambar 11. Tempe mentah

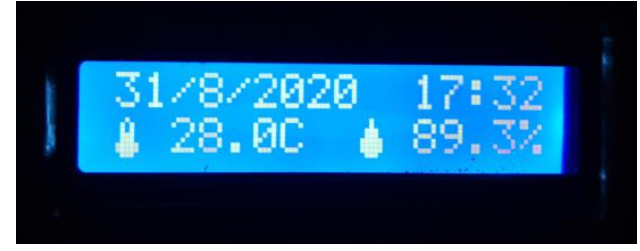

Gambar 12. Tampilan LCD alat aktif

Selanjutnya sensor suhu akan membaca suhu pada inkubator apabila suhu terbaca kecil $32^{\circ} \mathrm{C}$ maka akan menyalakan lampu pemanas sedangkan apabila suhu melebihi dari $35^{\circ} \mathrm{C}$ maka relay akan mematikan sebagian pemanas dan mengaktifkan kipas sebagai penurun suhu jika melebihi set point yang ditetapkan. Alat ini akan bekerja selama 16 jam, jadi selama 16 jam alat akan tetap mengontrol suhu dan kelembaban sampai batas waktu yang ditentukan. Jika alat telah bekerja selama 16 jam maka otomatis alat akan mati dan proses fermentasi sudah bisa diangkat dari inkubator

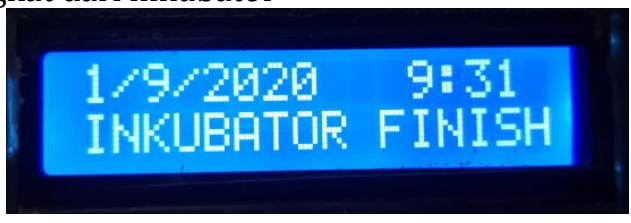

Gambar 13. Tampilan LCD alat selesai

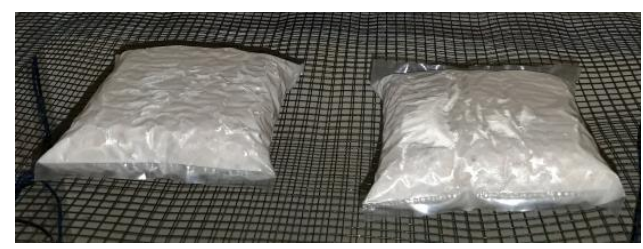

Gambar 14. Tempe matang

E. Pengujian aplikasi.

Pengujian aplikasi yaitu menguji alat dengan cara memonitoring melalui aplikasi blynk, dimana pengguna bisa mengakses data secara online dengan jarak jauh hanya menggunakan aplikasi android, selama sistem kontrol terhubung dengan jaringan internet maka data masihdapat diakses dari jarak jauh

Pada aplikasi blynk akan memonitoring dan me-record parameter suhu dan kelembaban pada ruang inkubator secara real time. 


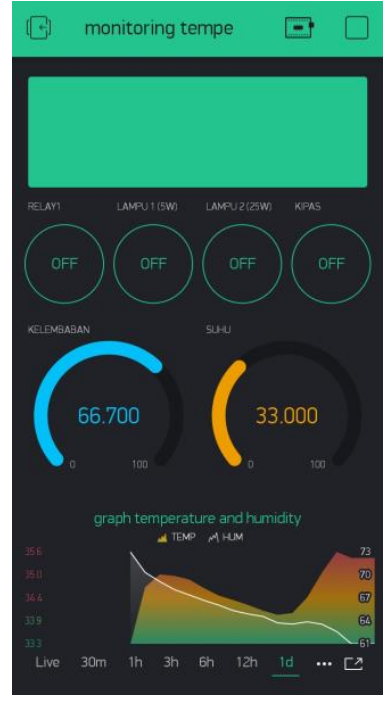

Gambar 15. Tampilan aplikasi blynk

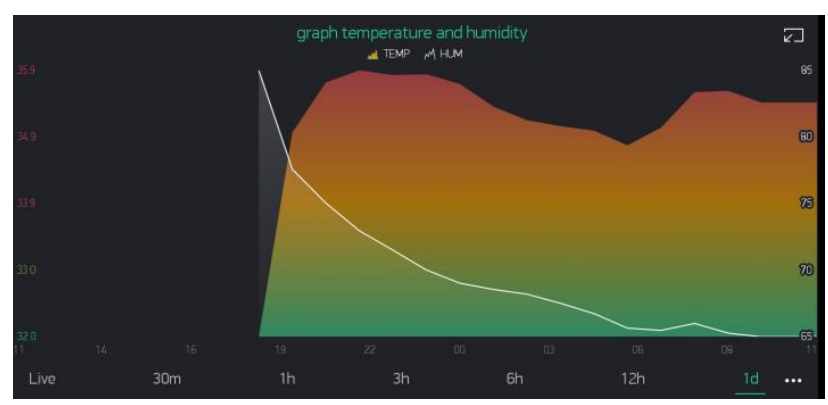

Gambar 16. Tampilan grafik temperatur dan kelembaban

Pada gambar 16 terlihat bahwa grafik suhu ditunjukan dengan gradian warna dan untuk kelembaban ditunjukan dengan garis putih. Pada grafik dapat disimpulkan perbandingan suhu dan kelembaban berbanding terbalik, pada grafik terlihat rata-rata suhu berada pada $34,2^{\circ} \mathrm{C}$ $34,8^{\circ} \mathrm{C}$ dan kelembaban mengalami perubahan dari $85 \%$ $65 \%$ pada grafik bisa melihat secara real time dan per waktu.

\section{Penutup}

Hasil dari pengujian inkubator fermentasi ini dapat disimpulkan bahwa:

1. Proses inkubator fermentasi tempe berjalan selama 16 jam lebih cepat dari proses tradisional.

2. Sistem kontrol dapat dimonitoring dari jarak jauh.

3. Pada proses monitoring suhu dan kelembaban menggunakan aplikasi blynk dan menampilkan data secara real time.

\section{REFERENSI}

[1] I. Idris, R. A. Sari, W. Wulandari, and W. U, "Pengendalian Kualitas Tempe Dengan Metode Seven Tools," Teknovasi, vol. 3, no. 1, pp. 66-80, 2016.

[2] A. Kurniawan, "Sistem Kendali Suhu Dan Kelembaban Untuk Optimasi Proses Pembuatan Tempe Berbasis Mikrokontroler," Univ. Pembang. Nas. "Veteran" Jawa Timur, 2012.

[3] A. Muhamad Widodo and Sukarni, "Rancang Bangun Alat Kendali Suhu Dan Kelembaban Untuk Optimasi Proses Pembuatan Tempe," Cyber-Techn, vol. 13, no. 02, pp. 95-104, 2019.

[4] A. Setyawan et al., "Kelembaban Untuk Optimasi Proses Pembuatan Tempe Pada Skala Industri Rumah," Desain Alat Sist. Kontrol Suhu Dan Kelembaban Untuk Optimasi Proses Pembuatan Tempe Pada Skala Ind. Rumah Tangga, 2013.

[5] G. Dewantoro, S. Hartini, and A. H. Waluyo, "Alat Optimasi Suhu dan Kelembaban untuk Inkubasi Fermentasi dan Pengeringan Pasca Fermentasi," J. Rekayasa Elektr., vol. 11, no. 3, 2015.

[6] Sensirion, "Datasheet SHT1x (SHT10, SHT11, SHT15) Humidity and Temperature Sensor IC," Sensirion, no. 5, pp. 1-12, 2011.

[7] Handsontec, "ESP8266 Datasheet," Hanson Technol., 2017.

[8] D. A. O. Turang, "Pengembangan Sistem Relay Pengendalian Dan Penghematan Pemakaian Lampu Berbasis Mobile," in Seminar Nasional Informatika (SEMNASIF), 2015.

[9] A. Budiyanto, G. B. Pramudita, and S. Adinandra, "Kontrol Relay dan Kecepatan Kipas Angin Direct Current (DC) dengan Sensor Suhu LM35 Berbasis Internet of Things (IoT)," Techné J. Ilm. Elektrotek., 2020.

[10] "Perancangan Sistem Suhu Otomatis Dan Pengaturan Posisi Telur Pada Penetas Telur Berbasis Arduino," J. Karya Ilm. Tek. Elektro, 2018.

\section{Biodata Penulis}

Berdi Gunawan, lahir di Padang, 5 Oktober 1996. Menyelesaikan studi DIV Teknik Elektro Industri pada Jurusan Teknik Elektro Fakultas Teknik Universitas Negeri Padang.[1]

Dr.Sukardi, M.T, lahir di Semerap Kerinci, 10 Mei 1961. menempuh pendidikan di Kerinci sejak SD, SMP dan SMA, melanjutkan kuliah Sarjana (S1) di IKIP Padang Indonesia Jurusan Pendidikan Teknik Eleltro, Magister (S2) Teknik ELektro di Institut Teknologi Bandung, dan Program Doktor (S3) bidang Pendidikan Teknologi dan Kejuruan di Pascasarjana Universitas Negeri Yogyakarta. Saat ini bertugas sebagai Dosen dan menekukni riset bidang Pendidikan Teknologi dan Kejuruan Ketenagalistrikan. ${ }^{[2]}$ 